\title{
Creative Transformation of Etiquette- A Case Study of Honorers in Etiquette Teaching
}

\author{
Feng Qiong ${ }^{1}$ \\ ${ }^{1}$ General Education Department, Sichuan University Jinjiang College, Meishan, China
}

\begin{abstract}
Under the tide of reviving traditional culture, Chinese "ritual" culture education, which is the core of traditional culture, is in full swing. The state proposes that traditional culture needs creative transformation. However, how to transform the traditional ritual culture and the contents are not pointed out in detail. In contemporary etiquette teaching, both traditional etiquette and modern etiquette, enjoy many priority rights. From five aspects, this paper analyzes that the "venerable person" needs to be reconstructed urgently, and draws the conclusion that under the background of globalization and the Internet age, both sides of interpersonal communication should stand on an equal footing and regard life as the object of respect.
\end{abstract}

\section{INTRODUCTION}

In modern etiquette teaching, whether it is business etiquette, service etiquette or government etiquette, there are several contents related to honorees in interpersonal communication rules, such as "honorees have the priority to decide when shaking hands", "honorees have the priority to know when introducing", "honorees are arranged in the upper position when seated", "honorees have priority when serving tea", "honorees are superior when issuing business cards" and so on.(table I) What is an honorable person? Mencius said, "There are three respects in the world: one for Jue, one for tooth and one for virtue". That is, people with high positions, people with old ages, and people with high moral character. Although the object of respect in modern etiquette has changed compared with Mencius' judgment, the " honorable person" refers to the person with high position, the elder, the lady and the guest according to the specific arrangement order.

TABLE I. UNEQUAL RELATONSHIPS

\begin{tabular}{|c|c|c|}
\hline Relationship & Venerable & $\begin{array}{c}\text { Rights enjoyed by venerable } \\
\text { persons }\end{array}$ \\
\hline $\begin{array}{l}\text { parent-child } \\
\text { relationship }\end{array}$ & parent & \multirow{4}{*}{$\begin{array}{l}\text { honorees decide when shaking } \\
\text { hands } \\
\text { honorees have the priority to know } \\
\text { when introducing } \\
\text { honorees are arranged in the upper } \\
\text { position when seated } \\
\text { honorees have priority when } \\
\text { serving tea } \\
\text { honorees are superior when issuing } \\
\text { business cards }\end{array}$} \\
\hline $\begin{array}{l}\text { subordinate } \\
\text { relationship }\end{array}$ & Superior & \\
\hline $\begin{array}{l}\text { Relationship } \\
\text { between } \\
\text { elders } \\
\text { and juniors }\end{array}$ & elder & \\
\hline $\begin{array}{l}\text { Host-guest } \\
\text { relationship }\end{array}$ & guest & \\
\hline
\end{tabular}

In fact, the high-ranking people, the elderly and the ladies are similar to the three principles in traditional thinking, "Jun is the minister, father is the son, and husband is the wife". That is, in the workplace, at home, and in men's and women's communication, there is an order of superiority and inferiority, and the two sides are not in an equal position to talk.

Jun is a minister, so his superiors always have an advantage in seating arrangement, tea order, introduction, handshake, greeting and other etiquette. The same is true for a father as a child. The only major adjustment is to change the traditional "men are superior to women" into today's "lady first" and "respect women", and treat women as the weak who need care and protection. In a word, people in these three relationships do not talk on an equal order. This rule of handover has not kept pace with the idea of "democracy, freedom and equality" advocated by our country at present.

\section{THE REASON WHY THE ETIQUETTE TEACHING "HONOUR PERSON" NEEDS TO BE RECONSTRUCTED}

\subsection{The root of the ceremony: accompanied by inequality}

Rites have long been an important means of social regulation in China, so traditional China is called "the rule of rites". The so-called "rule by etiquette", in a nutshell, is to maintain and coordinate the relationship between human relations and grades through the contents and means of "etiquette system", "etiquette" and "ritual vessels", so as to achieve social stability and firm rule. This also means that rites are associated with the hierarchical differences in human society. There is no 
ceremony in the primitive clan society of equality and integration. Rites are the product of the development of human society to a certain stage. ${ }^{[1]}$

Rites in China originated from the ritual activities of primitive ancestors from $3500 \mathrm{BC}$ to $2000 \mathrm{BC}$, and the sacrifices of witches and wishes can represent the people's access to God's will. At that time, science was not developed, and people thought that thunder and lightning and good harvest were all related to Gods, so they needed witches and prayers to sacrifice to Gods. When offering sacrifices, people take out the best things in their homes and offer them to the Gods. Wu and Zhu will take these sacrificial objects as their own after the sacrifice, and some objects will be buried in the tomb after their death. In order to make this possession sustainable, they compiled a set of rules, which was the original ritual system. Later, dynasties changed and monarchs changed, but what remained unchanged was the feudal etiquette rule for thousands of years.

As Professor Yang Zhigang said: "the emergence of rites means that with the change of social relations, people's ethical and moral concepts have undergone tremendous changes. Starting from the concept of rites, the "unreasonable" phenomenon of inequality between rich and poor and hierarchical differentiation becomes "reasonable". The ruling class has achieved social stability and development, as well as the firmness of its own rule, by transforming "unreasonable" grade differences into propriety differences and taking them as a fundamental order and law. ${ }^{[1]}$ ”,

\subsection{The order of all kinds of inequality, the essence is to practice the hierarchy}

In the feudal society of China, people's daily life, such as food, clothing, housing, transportation, sacrifice and festivals, were all bound by "rites". For example, Confucius said, "eight dancing in court is intolerable", which reflects that the princes overstepped the etiquette system and watched music and dance performances on the scale of the emperor, which made Confucius feel unbearable. "The essence of feudal politics is to maintain the hierarchy of superiority and inferiority, and the main manifestation of lifestyle ideology is the ubiquitous maintenance of hierarchy sequence. Life is real, drinking, eating, wearing a hat, and having specific and vivid styles and contents. In China, food, clothing, housing and transportation, festivals, leisure and entertainment, and daily utensils have become the carriers of the hierarchical sequence without exception. " [2]

Professor Peng Lin made a wonderful exposition on the respect and inferiority of Chinese etiquette in Essentials of Chinese Etiquette: "the characteristic of Chinese etiquette is that each other regards each other as an honorable person and themselves as inferior people. Because everyone is like this, they are actually equal, and everyone is an honorable person. " [3]

"What Li Yun said:' father is kind, son is filial; elder brother is friendly, little brother is respectful, husband's righteousness, women listen; To be friends, to be partners, to be faithful, to be kings, to be worthy men of letters, and to be courtiers, to be loyal-they mean ten righteousness. " With these kinds of righteousness, your responsibility is to be loyal to righteousness and realize righteousness, because that is why you complete your own concept of human being. Therefore, you are committed to righteousness, not your opponent, who is just the object through which righteousness is expressed. Then, when a minister, a son or a woman martyred a gentleman, a father or a husband, it was a gentleman, a father or a husband who was martyred, not an individual who represented him. Therefore, no matter what the individual is, your abstract concept of him or her is absolute, and' all things are parents' is meaningful under this explanation. However, in this way, if you expect the other party to implement its abstract concept, it will fall into the hands of the dominant, and the controlled person will not enjoy this right. " [4]

In today's etiquette teaching, the introduction, handshake, business card handing, toast, seating and other etiquette are arranged in order, and the priority is still in the hands of "excellent performers" such as those with high positions and the elderly. "The order of practicing rites is just the concrete manifestation of the hierarchy of rites. In turn, through the specific etiquette and the order it requires, the hierarchy of rites has been continuously strengthened. " [1]

Nowadays, the emerging forces entering the workplace-post-90 generation and they grew up under the educational background of frequent international exchanges, integration of Chinese and Western cultures, democracy, freedom and equality. University education, vocational training, and then promoting the hierarchical system will be scorned by them, which is also very outdated. Moreover, we can see that in the Internet information age in real life, the market is changing rapidly and the products are changing rapidly. Many Internet companies no longer pay attention to the hierarchical ranking of superior and inferior. In a relaxed and pleasant atmosphere, people collide and communicate equally, which is more conducive to efficient communication, project innovation and rapid development of the company. Therefore, it is very important to establish an equal dialogue mechanism in the whole social interpersonal communication process.

Although we are aware of the urgency of this problem, "we are still not prepared enough for the survival mode of establishing equal relations. People's hearts have been expecting to feel accepted by others, but somehow, their minds don't always understand how to do it. Without this feeling of equality among all people, this may be the real reason for the war. "

\subsection{Into the hierarchy of daily life etiquette, suppress people's personality}

China's "rites" are integrated into every aspect of daily life, which can be realized mainly through externalized etiquette system, internalized self-cultivation and social moral supervision by public opinion. Qian Mu said: "rite" is a family rule, which manages all the housework and foreign affairs of life, death and marriage. Similarly, "courtesy" is also a government guideline, governing all 
internal affairs and diplomacy, such as the relationship between the government and the people, conscription, signing peace treaty and inheritance rights, and so on. ${ }^{[6]}$ Descriptively speaking, "ritual" presents a form that integrates the four aspects of individual, family, country and the world. In this way, as a comprehensive concept, "etiquette" contains various etiquette about personal activities, social relations, political organizations and religious behaviors. It essentially contains all aspects of human culture: psychological, social and religious aspects. Within the scope of Confucianism, it is unimaginable for a person to become a real person without going through the process of "etiquette". This ritualization here means humanization. ${ }^{[7]}$

Professor Peng Lin also pointed out in the Essentials of Chinese Etiquette that there are two unequal relations of respect and inferiority: one is between the monarch and his subjects, and the other is between father and son. He believes that national leaders are respected people and should be taken for granted; it's natural for a father to respect his son. "The reason why Confucianism wants to establish the superiority and inferiority between father and son is to cultivate children's respect for the elderly. If there is no respect for their parents, how can we achieve' respect my elder, and other old people'? If we excessively advocate equality, as a result, the tradition of respecting the elderly, which has been passed down for thousands of years, disappears, so that the atmosphere of giving seats to the elderly cannot be advocated. The relationship between father and son seems to be unequal. In fact, when a son grows up, he is a father and a respectable person, so this is fair to everyone. " ${ }^{[3]}$ That is to say, only when he becomes the father of others can he enjoy the authority and interests of his father. In the relationship between him and his father, the child is always in a low position. At this time, "the relationship between people is: one person is above, the other is below. And this cannot produce a true connection between people. " ${ }^{[10]}$ Because the other party is king, father and elder, we have to respect each other, wronged ourselves and give up our position. So when we meet superiors, parents and elders who are not worthy of respect? Are we subject to identity, authority and status?

In Chinese family education, parents often make decisions instead of children. "I have eaten more salt than you have eaten, and I have walked more bridges than you have walked." So you have to listen to me. "Turn a deaf ear to old man's words, and suffer losses immediately." We teach our children to listen to their parents or grandparents at home, and to listen to their teachers at school. You want him to obey, he listens to other people's arrangements, and his own heart is ignored. Such a child is easy to grow into a person with low self-esteem, and always takes other people's evaluation as the standard to please others and meet their needs. Such education "will be the source of training a restricted, non-creative and ignorant person." [5]

The challenge we face today is to make every family and individual in the family feel superior. Thousands of happy and well-adapted people come from different family models. But there are also many people living in inefficient families. The difference lies not in the external form, but in the relationship within the family. What we need to do in particular is to replace this dominantsubmissive relationship. ${ }^{[5]}$

This paper holds that the unequal ethical concept of hierarchy and paternalism is unfavorable to the independence of individual personality and the development of the times. "The so-called teaching of politeness and courtesy, worships love others without oneself." [11] The long-term disciplined body and repressed personality make children become the silent majority in the face of the invasion of power.

Confucian ethics has brought far-reaching influence on Chinese interpersonal communication by blending human relations with human feelings. On the one hand, consanguinity and affection are stained with ethics; on the other hand, philosophy and ethics are rooted in daily life, which leads to the long-term, stable, harmonious and unequal social interaction of Chinese people. However, from the personality point of view, feelings change from individual to relationship, and after being regulated by "courtesy", they can only suppress themselves, resulting in individual behavior often being subject to others. ${ }^{[12]}$

In our real life, the negative effects and legacy of ritual tradition still exist. The patriarchal and hierarchical nature of rites, the subordinate concept brought about by them, the suppression and distortion of human nature, and the value orientation of "emphasizing the essence and suppressing the end"; the principle of "loving rites and saving sheep", and the formalism that comes from it, and the conservative psychology of following the old; all kinds of untimely and even harmful "rules of the game" appearing in the appearance of "courtesy" ... all of these still bother Chinese people to move towards modern life to varying degrees. ${ }^{[13]}$

"The use of courtesy, harmony is the most important", so that there are differences in equality and an orderly state "has played an important role in uniting the country with the broad masses of people. However, it is this stable inheritance mechanism that causes the national psychology to bear the heavy burden of feudal culture, so that the suppression of personality reaches the maximum intensity. In the past hundred years, Chinese ideological enlightenment often originated from the field of life and impacted ethical politics, which is a major feature of cultural modernization caused by the Trinity traditional cultural model. Therefore, diluting the intervention of ideology, returning to life as a personal choice, and promoting the disintegration of the Trinity feudal cultural model are the only way to liberate China's personality. " [14]

\subsection{Great changes have taken place in the times, and interpersonal relationships have broken away from traditional ethics}

In the agricultural society for thousands of years, the traditional rule of etiquette can become a reality, because the land, lifestyle and interpersonal relationship rarely change. Just as Mr. Fei Xiaotong said in "rural China": "the local society is a society that was born, raised and died in the same place. Not only does the population flow 
very little, but also the land that people take for resources rarely changes. In this environment, regardless of the Qin and Han Dynasties, from generation to generation, individuals can not only trust their own experiences, but also trust their ancestors' experiences. An old farmer farming in a local society is only confronted with the change of seasons, not the change of times. Once a year, it goes back and forth. The solutions used by predecessors to solve life problems can be copied as a guide to their own lives. The more it has been proved to be effective in previous generations' life, the more it deserves to be conservative. Therefore, "words must be obedient", and good antiquity is the guarantee of life." ${ }^{[15]}$

The traditional society is a five-ethics society, which is what Mencius said: "father and son have relatives, monarch and minister have righteousness, couples are different, the young and old are in order, and friends have faith", because it was an acquaintance society and a society of "ruling by courtesy". However, today is the information age, network communication is becoming more and more frequent, and the interaction between strangers is becoming more and more common. Rural labor poured into cities and towns, and villages became "hollow villages" and "empty nest villages". "In the process of farmers' mobility, there will be differentiation in living space, occupation and class." ${ }^{[16]}$ In the era of innovation and entrepreneurship, there are more and more freelancers who rely on the Internet to make a living in both urban and rural areas. In Wechat business, online celebrity, small videos, live broadcasts, online audio classes, homestays, etc. many people engaged in these professions have broken away from the affiliation of traditional organizations, and even if they hold a group, they will cooperate as partners in an equal mode. In addition, there are many online communities among strangers in the city: "mother group", "owner group", "fruit group", "flower group" and "supermarket group" ... Although living in the same community, many people have never met each other, and even if they face each other, they don't know each other, but this does not prevent people from chatting enthusiastically in WeChat group. Thus, the rules of interpersonal communication in ancient etiquette or contemporary etiquette books: superiors, elders, ladies and guests seem to be no longer applicable. Just as Fei Xiaotong said: "In a fast-changing society, the effectiveness of tradition cannot be guaranteed. Although a way of living has been effective in the past, if the environment changes, no one can deal with new problems in the old way. " ${ }^{[15]}$

"The ritual of becoming a mass phenomenon, especially the ritual that can be spread to later generations, is definitely not something that can be formulated and effective by someone or an organ; if you want to be effective, you must have living conditions as the basis." [4] From the traditional agricultural society to the information age of the network, people's living conditions and ways have undergone tremendous changes, and the scope and mode of interpersonal communication have also changed. The "etiquette" used to standardize interpersonal communication standards also needs to be changed.

\subsection{The present situation of etiquette education, which is separated from tradition and modernity, has intensified the spread of bad ideas.}

Nowadays, the country is vigorously advocating the promotion of traditional culture and strengthening cultural self-confidence. General Secretary Xi Jinping pointed out in "Promoting the Creative Transformation and Innovative Development of Chinese Excellent Traditional Culture": "do not forget that you can open up the future and be good at inheritance to be better innovative." We should uphold an objective, scientific, courteous attitude, do not go back to ancient times, do not simply deny, persist in making the past serve the present, bring forth the new, treat it with discrimination, inherit it with sublation, take its essence and discard its dross, and use all the spiritual wealth created by the Chinese nation to educate people with culture and literature. According to the characteristics and requirements of the times, we should reform the connotations and old expressions that still have reference value, endow them with new connotations of the times and modern expressions, and activate their vitality. According to the new progress of the times, we should supplement, expand and perfect the connotation of Chinese excellent traditional culture, enhance its influence and appeal, realize the creative transformation and innovative development of Chinese excellent traditional culture, and let Chinese culture show permanent charm and style of the times. ${ }^{[8]}$ However, at present, we have to face the fact that: "the etiquette education in our country is characterized by two extremes, either staying at the level of traditional Confucian classics interpretation, lacking certain timeliness and operability; either pure transplantation of western etiquette, embedded in the soil of Chinese culture is somewhat different. There are obvious deficiencies in practice, moral education and social orientation. " ${ }^{[9]}$

Chinese traditional "rites" have a history of thousands of years, and the literature is vast. It contains various classics of rites, such as Book of Rites, Zhou Rites and Yi Rites, official texts of dynasties, family rites and allusions circulated among the people, etc. It also includes etiquette, ritual, etiquette, ceremony and so on, including people's life and death, food, clothing, housing and transportation. Therefore, some scholars believe that "etiquette" is equivalent to Chinese traditional culture. Chinese traditional etiquette is mostly classical literature, which is difficult to understand. To study it requires profound cultural foundation, and the economic benefits are not obvious, so only a few researchers, university professors and scholars are doing it. For example, Professor Peng Lin of Tsinghua University, Professor Yang Zhigang of Fudan University, researcher Liu Zhiqin of Chinese Academy of Social Sciences and so on. They trace history, research phenomena, or comment or discuss. They realize that traditional culture needs creative transformation, but what aspects of transformation, how to keep up with the times and how to keep up with the pace of people's needs have not been pointed out in detail.

Under the background of the revival of traditional culture, various "Chinese studies classes" and "traditional etiquette" training classes are in full swing. However, 
good and bad mix together. For example, some training institutions continue to sing the outdated "female virtue" as a Chinese virtue.

The education and training of modern etiquette mainly focus on personal image (make-up, costume matching, physical training, etc.), interpersonal communication (banquet etiquette, reception etiquette, public etiquette, etc.), and industry etiquette (business, banking, hotel, government affairs, aviation and other industries). Professor Jin Zhengkun of Renmin University of China and Professor Li Rongjian of Wuhan University are all disseminators of modern etiquette, and etiquette textbooks published by other universities are similar. Turn on these etiquette books, and introduce the western etiquette content of communication etiquette, such as wearing suits, playing ties, makeup skills, elegant body, red wine, coffee, western food, hugging and shaking hands. Because it doesn't need to have profound knowledge of ancient Chinese literature to study traditional literature, its content is relatively solid and it has considerable economic returns, which leads to people from all walks of life flooding into etiquette training industry. Sometimes, you only need to attend a crash course for a few days, you can become an internationally registered senior etiquette trainer, and you can also seal yourself as a etiquette expert, master, expert committee member, etc. I found that many teachers are using the same powerpoint for different students, and some people can't even do it. Dance teachers, body teachers, flight attendants, etiquette teachers in vocational colleges are more practitioners. This kind of etiquette training is mostly scripted, and the westernized training content has limited significance to the shaping of personal connotation and the spiritual and cultural construction of the whole society.

Basically, no one in modern academic circles has effectively grafted modern practical etiquette with excellent traditional etiquette. The mixed etiquette teachers and the separated teaching contents between tradition and modernity have accelerated the spread of bad etiquette thoughts in society.

\section{THE WAY TO RECONSTRUCT THE "RESPECTED PERSON" IN ETIQUETTE TEACHING}

Today, we are pursuing the revival of traditional culture, looking for cultural confidence and standing in the forest of the world. However, it is not a copy of traditional culture, because the whole social background is no longer a traditional acquaintance agricultural society, but a rapidly changing information age, with great changes in interpersonal relationships, time background and working methods. We need to critically inherit the traditional culture.

The reconstruction of traditional etiquette must be the integration of Chinese traditional culture and modern civilization, and the reconstruction of family ethical order based on independence and equality. The reconstruction of traditional etiquette should also be carried out on the premise of maintaining individual dignity and value, abandoning the content that is not suitable for modern society, retaining the connotation that can show affection and modern value, preserving the warm Chinese etiquette characteristics, and pursuing and answering "what is a good life". ${ }^{[17]}$

\section{1 human relations should be equal}

Reconstructing the "respected person" in etiquette teaching means that both parties should stand on an equal position, that is, the family ethical order should be equal. "When we achieve equality, the family will become stronger. We will cultivate more competitive people. " [5] And the family unit is integrated with its parents and society. The family itself and what the family teaches to everyone is the key to achieving social harmony. ${ }^{[5]}$

In the family, parents respect their children and do not need him to "obey", "be gentle" and "obey" everything; he doesn't need to live as an adult's face and glorify his ancestors; there is no need to "raise children to take care of themselves when they become old", and parents are responsible for their own lives. Parents allow their children to talk with their families on an equal footing, and make their favorite choices in choosing school, choosing a career, choosing a spouse and living style. Children respect their parents, respect their arrangements for their work, marriage, lifestyle, financial distribution, etc, and don't force their parents to buy a house, buy a car and take care of their children ... We are living under the same roof, loving each other, respecting and being independent.

Within an organization, superiors respect subordinates and stop bossing them around. The lower level respects the higher level, so there is no need to grovel. Everyone works together in an equal manner, and standardizes words and deeds in a way that is more conducive to the development of the company. Outside the organization, staff respect customers without flattering them; customers don't stand high in the attitude of God, but talk to each other on an equal footing and win-win cooperation.

"Every leader is a individual, every child is independent, and both men and women are human beings. Decision-making, authority and goals all contain the most basic meaning of being human when people get along. " [5] Therefore, we respect everyone equally!

\subsection{Taking life as the object of respect}

Reconstructing the "honorees" in etiquette teaching, the specific objects of respect should be the same. We no longer take the "venerable person", that is, the elderly, the high-ranking person, the person with good virtue, or the person with physical discomfort, such as "the old, the weak, the sick, the disabled and the pregnant", as the object. We respect life! It only happens once and its time is limited. This is respect regardless of men and women, young and old, high or low position, poverty and wealth, integrity and disability, and it is the dignity and dignity that people should be born with.

"Only by truly respecting people's life individuals and attaching importance to the individual values and social values contained in life etiquette can we create a solid 
family and social foundation and achieve good social governance goals." ${ }^{[17]}$

Life is only once, and everyone has the right to describe it as his favorite color. First of all, we should respect ourselves, love our own life, and don't have to grovel to please others. At home, in the company and in the society, we express our views freely and honestly with an equal attitude, have more exchanges and collisions with others, give full play to greater creativity, and the society will develop and progress faster.

At the same time, we also respect other people's lives and give them the greatest living space and freedom. If we all respect others' lives only once, perhaps there will be no incidents such as Sanlu milk powder, poisonous vaccine, gutter oil and big head doll. If we all respect other people's lives only once, perhaps there will be no scenes such as occupying emergency lanes indiscriminately and watching the fire. If we all respect other people's lives only once, maybe we won't force our children to live our faces, and they should jump off the building if they are "gay" and "with poor grades". If we all respect other people's lives only once, will the boss's superiors be less scolding, ordering and bossing? If we all respect other people's lives only once, will "cyber violence", "verbal criticism", "lever precision" and "keyboard man" converge a little, instead of pressing "Dr. An" and others to fall off the cliff?

\section{Conclusion}

"In the process of globalization, etiquette has become the sum of behavioral norms, norms and ceremonies formed by people in social interaction, aiming at establishing harmonious relations and conforming to the spirit of etiquette. Those international etiquette that not only contains the etiquette characteristics of different countries and nationalities, but also people of different countries and nationalities can understand each other are gradually taking shape. " [18] The concept of interpersonal communication that respects life in the attitude of equality of personality should be an international etiquette that conforms to the position of people of all nationalities in ancient and modern times and at home and abroad and can well unify human society.

\section{REFERENCES}

1. Yang Zhigang, Chinese etiquette system research, Shanghai: east China normal university press, 2000.

2. Liu Zhiqin, Chinese people's political consciousness, Long-standing articles are not enough, Beijing: Renmin University of China Press, 2012.

3. Peng Lin, Chinese Etiquette Essentials, Nanjing: Nanjing University Press, 2014.

4. Li Anzhai, A sociological study of rites and rites, Shanghai: Shanghai People's Publishing House, 2005.

5. virginia satir, The new peoplemaking, Trans. Yi Chunli, Ye Dongmei, etc, Beijing: Beijing Branch of World Book Publishing Co, Ltd, 2018.
6. Deng Erlin, Qian Mu and Qifangqiao World , Beijing: Social Science Literature Publishing House, 1995.

7. Du Weiming, Humanity and Self-cultivation, Trans. $\mathrm{Hu}$ Jun and $\mathrm{Yu}$ Minxiong, Beijing: China Peace Publishing House, 1988.

8. Propaganda Department of CPC Central Committee, Thirty Lectures on Xi Jinping Thought on Socialism with Chinese Characteristics for a New Era. Beijing: Learning Press, 2018.

9. Fu Qiong, Tang Yuan. Etiquette culture and the construction of public order , Changbai Journal, 2020 .

10. virginia satir, Connecting with people, Translated by $\mathrm{Yu}$ Bin, . Beijing: World Book Publishing Company Beijing Company , 2014.

11. Liang Shuming, Eastern and Western Culture and Philosophy ,Complete Works of Liang Shuming (Vol.1), Jinan: Shandong People's Publishing House, 1990.

12. Zhai Xuewei, Reproduction of human feelings, face and power, Beijing: Peking University Press, 2013.

13. Yang Zhigang, the creative transformation of etiquette and tradition, journal of Fudan university (social science edition), 1993.

14. Liu Zhiqin, History and life, The articles of the ages have not been exhausted , Beijing: Renmin University of China Press, 2012.

15. Fei Xiaotong, . Native China, Beijing: People's Publishing House, 2008.

16. Lu Yilong, Post-native China. Beijing: Commercial Press, 2017.

17. Xiao Fang, Jia Chen, Traditional life etiquette: how the past participated in the construction of the present, Journal of Social Sciences, 2020.

18. Jiang Jingping, Comparison of etiquette education between East and West , Journal of Xiangtan University, 2006 . 